\title{
Effect of Bio Field Treatment on the Physical and Thermal Characteristics of Vanadium Pentoxide Powders
}

\author{
Mahendra K Trivedi, Shrikant Patil* and Rama Mohan Tallapragada \\ Trivedi foundation,14747 N Northsight Blvd, Suite 111-136, Scottsdale, Az 85260, USA
}

\begin{abstract}
Vanadium pentoxide powders are very useful in producing ferrous as well as aluminiumalloys, inremoving carbon and sulphur and as catalysts in synthesizing ammonia and sulphuric acid. It is also used as corrosion inhibitor petroleum and chemical processing.

In the present investigation $\mathrm{V}_{2} \mathrm{O}_{5}$ powders are exposed to biofield. Both the exposed and unexposed powders are later characterized by various techniques. The average particle size is found to decrease with increase in number of days after treatment upto a maximum of $15.9 \%$ in 110 days indicating severe fracture at agglomerate/crystallite boundaries. The BET surface area showed a surprising decrease (it should increase as particle size is decreased) of $7.22 \%$ in 109 days indicating the surface densification/removal of sharp surface corners/formation of large particles. SEM photographs indeed showed that samples exposed to biofield after 20 days showed increase in size as well as rounded corners. Thermal analysis indicated an increase in melting temperature by $9.9 \%$ in samples treated after 57 days along with a much reduced change in weight.
\end{abstract}

X-ray diffraction of the powder samples indicated both increase and decrease in crystallite size, unit cell volume and molecular weight of samples exposed to biofield after 28, 104, 124 and 139 days.

These results indicate that the catalytic nature of vanadium pentoxide can be controlled by exposing to bio field and using after a specific number of days after exposure.

\section{Introduction}

It is known that electrical currents along with associated magnetic fields are present in human bodies. These are complex and dynamic mostly likely due to dynamical processes such as heart and brain function, blood and lymph flow, ion transport across cell membranes, and other biologic processes on many different scales [1]. Bio field is a cumulative effect exerted by these fields of human body on the surroundings. Typically, it may act directly on molecular structures, changing the conformation of molecules in functionally significant ways as well as may transfer bio-information through energy signals interacting directly with the energy fields of life.

Mr. Mahendra. K. Trivedi is known to transform the characteristics of various living and non living materials through bio field in his physical presence as well as through thought intervention. The details of several scientific investigations and the results in the form of original data are reported elsewhere [2-5].

The present paper reports the changes in the characteristics of Vanadium V Oxide powder after exposure to the bio field of Mr. Trivedi.

\section{Materials and Methods}

Vanadium pentoxide,Sigma Aldrich, $98+\%$ purity (here afterwards referred to as vanadium oxide) powders untreated (control) and treated by thought intervention through bio field were subsequently characterized by Laser particle size analyser, BET surface area, Thermal analysis and X-ray diffraction. These were then compared and the changes in characteristics after treatment were determined.

\section{Results}

\section{Particle size distribution by laser diffraction}

Typical data obtained using laser diffraction is given in table 1.The experiments were carried out for control (day1) and treated powders after $11,85,92$ and 110 days respectively.
Average particle size d50 and size exhibited by $99 \%$ of the powder particles $\mathrm{d} 99$ between treated and control powders were noted from the laser diffraction data tables. These values are given for both control and treated samples in table 2. The latter also gives the percent change

\begin{tabular}{|c|c|c|c|c|c|c|c|}
\hline \multicolumn{7}{|c|}{ Volume Size Distribution } \\
\hline $\mathrm{X}_{0} / \mu \mathrm{m}$ & $\mathrm{Q} 3 \%$ & $\mathrm{X}_{0} / \mu \mathrm{m}$ & $\mathrm{Q} 3 \%$ & $\mathrm{X}_{0} / \mu \mathrm{m}$ & $\mathrm{Q} 3 \%$ & $\mathrm{X}_{0} / \mu \mathrm{m}$ & $\mathrm{Q} 3 \%$ \\
\hline 4.50 & 0.80 & 18.50 & 1.64 & 75.00 & 9.00 & 305.00 & 81.47 \\
\hline 5.50 & 0.92 & 21.50 & 1.75 & 90.00 & 12.35 & 365.00 & 93.20 \\
\hline 6.50 & 1.02 & 25.00 & 1.90 & 105.00 & 15.97 & 435.00 & 98.01 \\
\hline 7.50 & 1.11 & 30.00 & 2.18 & 125.00 & 21.19 & 515.00 & 99.88 \\
\hline 9.00 & 1.22 & 37.50 & 2.79 & 150.00 & 28.40 & 615.00 & 99.88 \\
\hline 11.00 & 1.34 & 45.00 & 3.66 & 180.00 & 38.13 & 735.00 & 100.00 \\
\hline 13.00 & 1.43 & 52.50 & 4.76 & 215.00 & 50.61 & 875.00 & 100.00 \\
\hline 15.00 & 1.53 & 62.50 & 6.50 & 255.00 & 65.26 & & \\
\hline
\end{tabular}

\begin{tabular}{|l|l|l|}
\hline $\mathrm{X}_{10}=79.48 \mu \mathrm{m}$ & $\mathrm{X}_{50}=213.30 \mu \mathrm{m}$ & $\mathrm{X}_{90}=348.62 \mu \mathrm{m}$ \\
\hline $\mathrm{X}_{16}=105.10 \mu \mathrm{m}$ & $\mathrm{X}_{84}=317.92 \mu \mathrm{m}$ & $\mathrm{X}_{99}=492.74 \mu \mathrm{m}$ \\
\hline $\mathrm{VMD}=215 \mu \mathrm{m}$ & $\mathrm{C}_{-}$opt $=24.62 \%$ & \\
\hline
\end{tabular}

Table 1: Various particle sizes and percent particles (less than) in control vanadium oxide as recorded by laser particle size analyzer. Typically $9.00 \%$ of the particles $(\mathrm{Q} 3 \%)$ are present with volume size less than or equal to 75 micrometers $\left(x_{0}\right)$ and the average particle size $x_{50}$ is 213.30 micrometers.

*Corresponding author: Shrikant Patil, Trivedi foundation,14747 N Northsight Blvd, Suite 111-136, Scottsdale, Az 85260, USA, Tel: +1-650-229-4487; E-mail: research@trivedifoundation.org

Received October 31, 2012; Accepted December 28, 2012; Published January 05, 2013

Citation: Trivedi MK, Patil S, Tallapragada RM (2013) Effect of Bio Field Treatment on the Physical and Thermal Characteristics of Vanadium Pentoxide Powders. Material Sci Eng S11:001. doi:10.4172/2169-0022.S11-001

Copyright: (c) 2013 Trivedi MK, et al. This is an open-access article distributed under the terms of the Creative Commons Attribution License, which permits unrestricted use, distribution, and reproduction in any medium, provided the original author and source are credited. 
Citation: Trivedi MK, Patil S, Tallapragada RM (2013) Effect of Bio Field Treatment on the Physical and Thermal Characteristics of Vanadium Pentoxide Powders. J Material Sci Eng S11:001. doi:10.4172/2169-0022.S11-001

in $\mathrm{d} 50$ and $\mathrm{d} 99$ between various treated and control samples figure 1.

$\%$ change in $\mathrm{d}_{50}$ size $=100 \times\left(\mathrm{d}_{50}\right.$ treated $-\mathrm{d}_{50}$ control $) / \mathrm{d}_{50}$ control

$\%$ change in $\mathrm{d}_{99}$ size $=100 \times\left(\mathrm{d}_{99}\right.$ treated $-\mathrm{d}_{99}$ control $) / \mathrm{d}_{99}$ control

\section{BET Surface Area}

This is a well-known technique of physical adsorption of helium gas molecules on a solid surface. From the volume of gas adsorbed on a given mass of powder the specific surface area can be computed.

When a powder particle possesses high internal energy/rough and irregular surfaces/ fine size it exhibits a large BET surface area expressed in $\mathrm{m}^{2} / \mathrm{g}$. A high surface area powder is chemically and thermally very reactive and can be used as catalysts, paints, pharmaceuticals, etc.

$\%$ change in surface area $=100 \times($ surface area treated-surface area control)/surface area control

Surface areas had decreased by $1.41,4.11$ and $7.22 \%$ as the number of days after treatment changed to 14, 95 and 109 respectively. The decrease may be due to observed decrease in fine particles d50 and increase in coarse particles $\mathrm{d} 99$ as shown in figure 2 .

\section{Scanning electron microscopy}

Both control and after 20 days treated Vanadium oxide particles when examined in a scanning electron microscope did not show significant changes (Table 3). Rather both the powders showed agglomerated geometric shapes with particle sizes in the range $0.5-150$ micro meters and highly agglomerated intra particle boundaries (Table 4 and Figure 3).

\section{Thermo gravimetric analysis}

Mettler's simultaneous Thermo gravimetric analysis and Differential Thermo gravimetric analysis (combined TGA and DTG) unit was used for the experiments. The heating range and heating rate employed were respectively Room temperature to $900^{\circ}$ Celsius and $10^{\circ}$ Celsius/minute in Nitrogen atmosphere. From table 5 it can be noticed that the peak temperature in treated vanadium oxide after 57 days had increased by $9.9 \%$ from $666.87^{\circ} \mathrm{C}$ to $732.62^{\circ} \mathrm{C}$. The decrease in mass of the sample was not found to be significant.

\section{$\mathrm{X}$-ray diffraction}

$\mathrm{X}$-ray Diffraction (XRD) technique is sensitive at the atomic and crystal structure level. X-rays incident upon a material are diffracted by the atoms in various crystal planes and the wavelength and intensity of diffraction beams are monitored. The results are obtained in the form of a table as well as a chart of intensity of the spectral peaks on y axis and $2 \theta$ (twice the diffracted angle) on the $\mathrm{x}$ axis

(Bragg's law states that for conditions of $x$-ray diffraction $2 d$ sin $\theta=n \lambda$, where $\lambda$ is the wavelength of the incident $x$-rays, $\theta$ is the angle of diffraction and $n$ is the order of spectrum usually taken to be 1 ).
The data obtained are compared with standard database of powder diffraction patterns of The International Centre for Diffraction Data (ICDD) to identify the Miller indices (the numbers that indicate the plane inside a crystal on which the diffraction takes place).

Normally X-ray diffraction is used to identify the crystal lattice, compute the lattice parameters ( $\mathrm{a}, \mathrm{b}$ and $\mathrm{c}$ which represent the distance between atoms on geometrical sides of a unit cell of a crystal, and, $\alpha$, $\beta$ and $\gamma$ the angles between the sides), concentration (assumed to be proportional to the intensity of the strongest peak corresponding to the substance in question), and average crystallite size (the size of a number of unit cells with orientations same in all three dimensions. This is also known as the size of the single crystal and can be obtained from the width of the peak at half maximum height).

$\mathrm{X}$-ray diffraction in the present experiments is used to evaluate apart from the usual parameters, the parameters that are related to energy changes with in and between atoms, such as the effective nuclear charge on the atom, the change in atomic weight the number of neutrons and protons etc.

A summary of the data obtained after analysis is given in the Table 5. The data is obtained for control sample (day 1) and samples treated with biofield after 28, 104, 124 and 139 days.

Both the control and treated samples are analysed using powder Phillips, Holland PW 1710 XRD system. A copper anode with nickel filter was used. The wavelength of the radiation is $1.54056 \AA\left(10^{-10} \mathrm{~m}\right.$ or $\left.10^{-8} \mathrm{~cm}\right)$.

\section{Data analysis}

The data is obtained in the form of $2 \theta$ Vs Intensity chart as well as a detailed table containing $2 \theta$, d value $\AA$, peak width $2 \theta$, peak intensity counts, relative Intensity $\%$, etc. The data was then analysed using PowderX software to obtain lattice parameters and unit cell volume.

$\theta^{0}$ values are converted from degrees to radians by multiplying with $\pi / 180$ or with 0.0175 . Similarly the peak width at half maximum is also converted to radians by multiplying with 0.0175 . Then the crystallite size $=\mathrm{k} \lambda / \mathrm{b} \operatorname{Cos} \theta$, where $\lambda$ is the wavelength of $\mathrm{x}$-radiation used and is $1.54056 \times 10^{-10} \mathrm{~m}$ and $\mathrm{k}$ is the equipment constant with a value 0.94 . The obtained crystallite size will be in nano meters or $10^{-9}$ meters.

Crystallite size in most ceramics can correspond to size of single crystal (arrangement of repetitive number of unit cells with same planar orientation). In metals, on the other hand crystallite size can also correspond to sub grain size in the single crystal.

Percent change in lattice parameter

It is the ratio of difference in lattice parameter of control and treated samples to the parameter of control sample expressed as percent.

Typically for the lattice parameter ' $a$ ' this is equal to $100 \times(\Delta \mathrm{a} / \mathrm{ac})$, where $\Delta \mathrm{a}=(\mathrm{at}-\mathrm{ac}) / \mathrm{ac}$.

\begin{tabular}{|c|c|c|c|c|}
\hline $\begin{array}{c}\text { NUMBER OF DAYS AFTER } \\
\text { TREATMENT }\end{array}$ & $\begin{array}{c}\text { AVERAGE PARTICLE SIZE d50 } \\
\text { Micrometers }\end{array}$ & $\begin{array}{c}\text { AVERAGE PARTICLE SIZE } \\
\text { d99 Micrometers }\end{array}$ & $\begin{array}{c}\text { PERCENT CHANGE BETWEEN } \\
\text { TREATED }\end{array}$ & $\begin{array}{c}\text { PERCENT CHANGE BETWEEN } \\
\text { TREATED and CONTROL d99 }\end{array}$ \\
\hline 1 & 213.3 & 432 & \\
\hline 11 & 222.5 & 492.7 & 4.3 \\
\hline 85 & 213 & 489.3 & -0.1 \\
\hline 92 & 200 & 432 & -6.2 \\
\hline 110 & 179.4 & 499.9 & -13.9 \\
\hline
\end{tabular}

Table 2: Particle size and percent change in particle size of bio field treated vanadium oxide powders and control powders. 
Citation: Trivedi MK, Patil S, Tallapragada RM (2013) Effect of Bio Field Treatment on the Physical and Thermal Characteristics of Vanadium Pentoxide Powders. J Material Sci Eng S11:001. doi:10.4172/2169-0022.S11-001

Page 3 of 4

Also known as strain, when multiplied with the elastic modulus it gives the force applied on the atoms. When the force is compressive the change is negative while a positive value indicates a stretching or tensile force.

The ratio difference in atomic weight between control and treated samples to the atomic weight of control sample is expressed as per cent change in atomic weight.

\section{$100 \times(\Delta \mathrm{M} / \mathrm{Mc})$ where $\Delta \mathrm{M}=(\mathrm{Mt}-\mathrm{Mc}) / \mathrm{Mc}$}

This value also represents the percent change in sum of protons and neutrons in the nucleus of the atom (Figure 4 and 5).

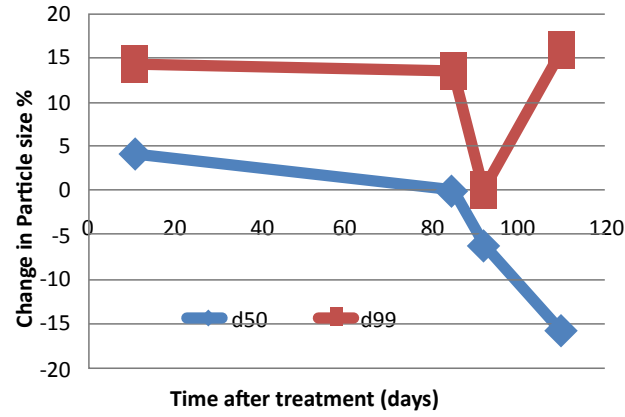

Figure 1: Percent change in $d_{50}$ and $d_{9}$ of treated Vanadium Oxide powders with change in number of days after bio field treatment. Both $d_{50}$ and $d_{99}$ showed an increase immediately after bio field treatment in 11 days followed by steady decrease till 85 days of treatment.After 85 days both the particle sizes rapidly decreased. However, d99 showed an increase possibly due to agglomeration of a number of small and medium particles.

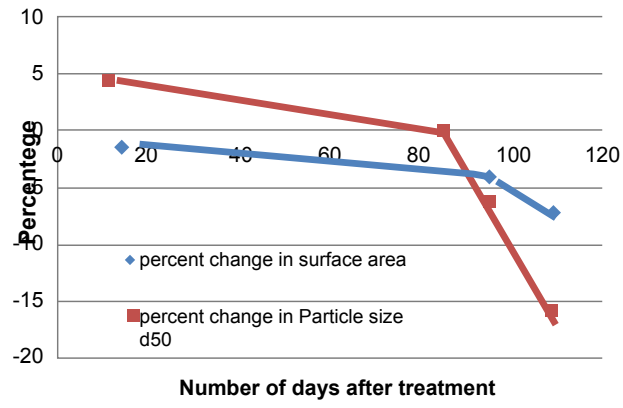

Figure 2: Percent change in particle size $d_{50}$ and surface area of treated Vanadium Oxide powders with change in number of days after treatment. As the decrease in surface area suggests an increase in particle size the observed decrease in particle size may be due to lose agglomerates where the gas is adsorbed in the internal boundaries also.

\begin{tabular}{|l|l|l|}
\hline $\begin{array}{l}\text { POWDER/ } \\
\text { CHARACTERISTIC }\end{array}$ & TREATMENT & $\begin{array}{l}\text { SURFACE AREA OF } \\
\text { VANADIUM OXIDEPOWDERS }\end{array}$ \\
\hline \multirow{3}{*}{$\begin{array}{l}\text { BET Surface area } \\
\mathrm{m}^{2} / \mathrm{g}\end{array}$} & CONTROL 1 day & 3.74 \\
\cline { 2 - 3 } & TREATED 14 days & 3.69 \\
\cline { 2 - 3 } & TREATED 95 days & 3.59 \\
\hline TREATED 109days & 3.47 \\
\hline $\begin{array}{l}\text { POWDER/ } \\
\text { CHARACTERISTIC }\end{array}$ & TREATMENT & VANADIUM OXIDE \\
\hline \multirow{2}{*}{$\begin{array}{l}\text { Change in surface } \\
\text { area \% }\end{array}$} & TREATED 14 days & -1.41 \\
\hline & TREATED 95 days & -4.11 \\
\cline { 2 - 3 } & TREATED 109days & -7.22 \\
\hline
\end{tabular}

Table 3: Surface area and percent change in surface area of control and bio field treated vanadium oxide powders.

\begin{tabular}{|l|c|c|}
\hline Powder/ characteristic & $\begin{array}{c}\text { Vanadium (v) oxide } \\
\text { Control }\end{array}$ & $\begin{array}{c}\text { Vanadium (v) oxide 57 } \\
\text { days after treatment }\end{array}$ \\
\hline Peak onset c & 624.60 & 718.53 \\
\hline Peak c & 666.87 & 732.62 \\
\hline Peak end pt. C & 723.23 & 757.67 \\
\hline Peak width c & 98.63 & 39.14 \\
\hline \%Change in weight at onset & 100.41 & 95.04 \\
\hline \%Change in weight at end pt. & 100.46 & 94.54 \\
\hline Total change in weight \% & 0.05 & -0.50 \\
\hline
\end{tabular}

Table 4: DTG-TGA analysis of control and biofield treated vanadium oxide powders indicating increase in exothermic peak temperature and relatively no significant change in the weight of treated powders.
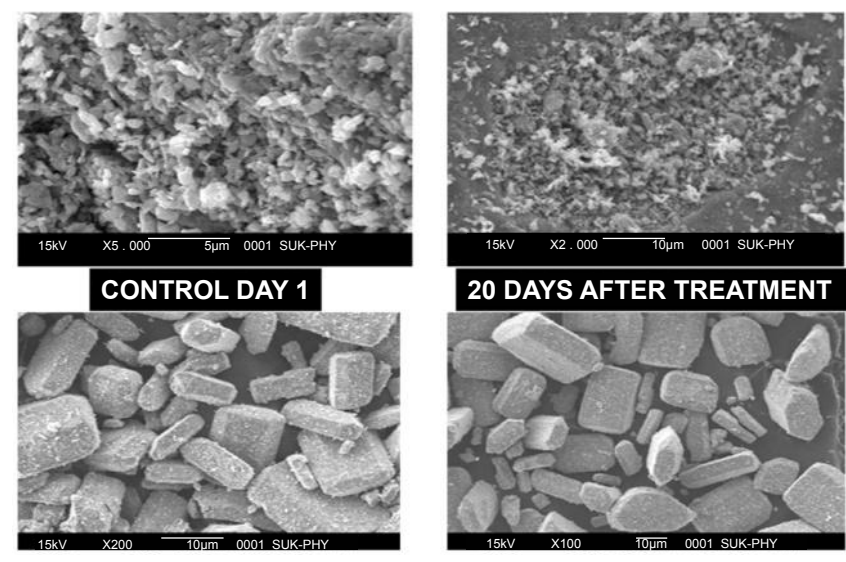

Figure 3: Scanning electron micrographs of control and bio field treated powders at two different magnifications showing no significant change in size of control and treated powders as well as agglomerates.

\begin{tabular}{|c|c|c|c|c|c|}
\hline \multirow{2}{*}{$\begin{array}{l}\text { Crystal/ atomic characteristic } \\
\text { computed from x-ray } \\
\text { diffraction data }\end{array}$} & \multicolumn{5}{|c|}{ Number of days after treatment } \\
\hline & 1 & 28 & 104 & 124 & 139 \\
\hline Lattice parameter 'a' x $10^{-8} \mathrm{~cm}$ & 11.5120 & 11.5199 & 11.5574 & 11.4709 & 11.5397 \\
\hline$\%$ change in 'a' & & 0.33 & -0.43 & 0.17 & 0.15 \\
\hline Volume of unit cell $\times 10^{-24}$ & 179.4 & 180.1 & 178.2 & 179.3 & 180.1 \\
\hline$\%$ change in volume of unit cell & & 0.40 & -0.65 & -0.02 & 0.39 \\
\hline Crystallite size ' $g$ ' x 10-9m & 84.94 & 70.78 & 84.94 & 60.67 & 141.55 \\
\hline$\%$ change in ' $g$ ' & & -16.67 & 0.01 & -28.57 & 66.65 \\
\hline $\begin{array}{l}\% \text { change in molecular weight } \\
\text { (weight of neutrons and } \\
\text { protons) mol\% }\end{array}$ & & 0.401 & -0.653 & -0.020 & 0.394 \\
\hline$\%$ change in density & & -0.399 & 0.658 & 0.020 & -0.392 \\
\hline
\end{tabular}

Table 5: XRD analysis of control and biofield treated vanadium oxide powders Using Powderx software volume of unit cell, crystallite size, molecular weight and density are evaluated.

From table 5 it was found that lattice parameter and unit cell volume increased with a resulting decrease in density (mass of unit cell/volume of unit cell). The crystallite size (size of single crystal grain) decreased indicating that the stresses due to expansion in unit cells might have caused fracture at weaker planes in the single crystal. Decrease in charge in the atom indicates that energy is wasconverted to mass as shown by increase in atomic weight.

\section{Conclusions}

- Laser diffraction had indicated that both the average particle 
Citation: Trivedi MK, Patil S, Tallapragada RM (2013) Effect of Bio Field Treatment on the Physical and Thermal Characteristics of Vanadium Pentoxide Powders. J Material Sci Eng S11:001. doi:10.4172/2169-0022.S11-001

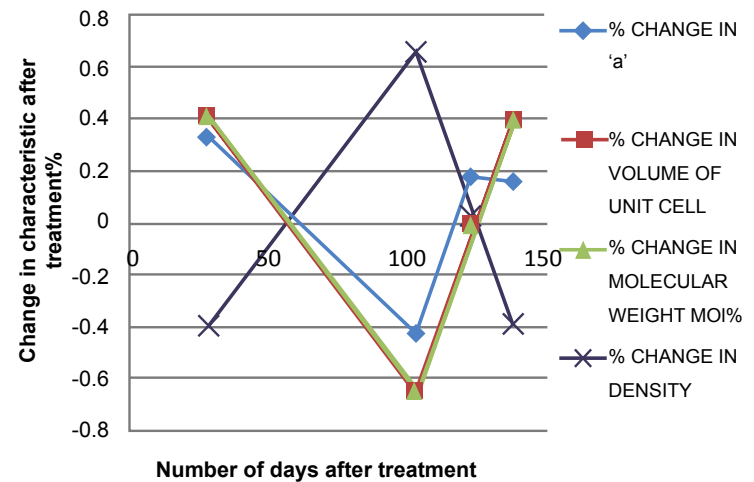

Figure 4: Changes in unit cell volume, lattice constant 'a' and molecular weight of treated Vanadium Oxide powders are similar while that exhibited by density is opposite.

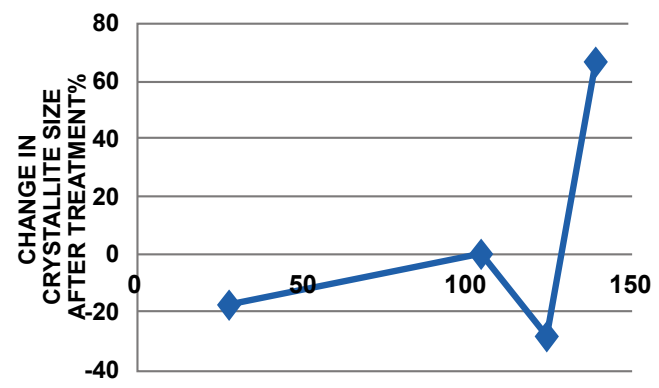

NUMBER OF DAYS AFTER TREATMENT

Figure 5: Change in crystallite size of treated Vanadium Oxide powders showing a sharp increase after 124 days of treatment indicating grain (crystal) growth.

size d59 and d99 showed an increase immediately after bio field treatment mostly due to agglomeration of particles. After 80 days of treatment the agglomerates of fine particles were broken while coarse particles further increased in size.
- As the number of days after bio field treatment changed from 14 through 95 to109, the surface area had decreased by 1.41 , 4.11 and $7.22 \%$ respectively. The decrease may be due to observed decrease in fine particles $\mathrm{d} 50$ and increase in coarse particles d99.

- The peak temperature in bio field treated vanadium oxide after 57 days had increased by $9.9 \%$ from $666.87 \mathrm{C}$ to $732.62 \mathrm{C}$. The decrease in mass of the sample was not found to be significant.

- Analysis of x-ray diffraction data led to the following inferences; treatment with bio field initially decreased the Lattice parameter, unit cell volume, molecular weight and crystallite size, while the density had increased. Exactly reverse had occurred after 124 days of treatment. The decreased crystallite size indicates the presence of stresses due to expansion in unit cells which may have caused fracture at weaker planes in the single crystal, and decreased molecular weight indicates that mass is converted to energy.

\section{Acknowledgement}

We thank Mr. Harish Shettigar for his active help, and the staff of various laboratories for conducting various characterization experiments. We also thank Dr. Cheng Dong of NLSC, Institute of Physics, and Chinese academy of Sciences for permitting us to use PowderX software for analysing XRD results.

\section{References}

1. Rubik B, Becker RO, Flower RG, Hazlewood CF, Liboff AR, et al Bioelectromagnetics Applications in Medicine. Alternative Medicine: Expanding Medical Horizons, A Report to the National Institutes of Health on Alternative Medical Systems and Practices in the United States.

2. http://trivediscience.com/mahendra-trivedi/Materials-Science

3. Technical trends (2008) Real-time results put pressure on fine grain theory Metal Powder Report 63: 24-31.

4. Dabhade VV, Tallapragada RMR, Trivedi MK (2009) Effect of external energy on atomic, crystalline and powder characteristics of antimony and bismuth powders. Bull Mater Sci 32: 471-479.

5. Trivedi MK, Tallapragada RR (2009) Effect of superconsciousness external energy on atomic, crystalline and powder characteristics of carbon allotrope powders. Mater Res Innov 13: 473-480. 